\title{
Effect of Methadone on Lipid Profile, Serum Leptin and Liver Enzymes Levels in Male and Female Rats
}

\author{
Zaligder Amir ${ }^{1(\mathbb{D})}$, Zarban Asghar ${ }^{2(\mathbb{D})}$, Sharifzadeh Gholamreza ${ }^{3(\mathbb{D}}$, Hosseini Mehran $\left.{ }^{4} \mathbb{(}\right)$, Tahergorabi \\ Zoya $5, *$ (D) \\ Member of Student Research Committee, School of Medicine, Birjand University of Medical Science, Birjand, Iran \\ Department of Clinical Biochemistry, School of Medicine, Birjand University of Medical Sciences, Birjand, Iran \\ 3 Assistant Professor, Social Determinants of Health Research Center, Department of Public Health, School of Health, \\ Birjand University of Medical Sciences, Birjand, Iran \\ 4 Department of Anatomical Sciences, Birjand University of Medical Sciences, Birjand, Iran \\ 5 Medical Toxicology and Drug Abuse Research Center, Birjand University of Medical Sciences, Birjand, Iran \\ * Correspondence: z.tahergorabi@yahoo.com (T.Z.);
}

Scopus Author ID 28168009900

Received: 30.07.2021; Revised: 25.09.2021; Accepted: 29.09.2021; Published: 18.11.2021

\begin{abstract}
Methadone Maintenance Therapy (MMT) has been accepted as a gold-standard treatment for opioid therapy. It may associate with adverse effects. This study aimed to affect methadone on serum lipid profile, leptin levels, and liver enzymes in male and female rats. 41 Wistar rats weighing 200$300 \mathrm{gr}$ were randomly assigned into four groups, including two methadone treatments and two control groups, both male and female, that received $5 \mathrm{mg} / \mathrm{kg}$ methadone or $1 \mathrm{cc}$ normal saline daily for 8 weeks respectively by gavage method. All animals were weighed weekly. Fasting blood sugar (FBS) was measured by a glucometer, and blood samples were taken by cardiac puncture for triglyceride, lowdensity lipoprotein (LDL), high-density lipoprotein (HDL), total cholesterol, Aspartate transaminase (AST), Alanine transaminase (ALT), alkaline phosphatase (ALP) and leptin levels measurement after 12h fasting. One-way ANOVA showed no significant difference in mean FBS, total cholesterol, triglyceride, and LDL levels among the four groups. Moreover, there was a statistically significant difference in the mean of HDL, ALT, AST, and ALP levels. Furthermore, repeated measures ANOVA indicated a significant increase in body weight of rats during 8 weeks. Our findings indicated changes in some metabolic effects associated with methadone treatment in a genderdependent manner.
\end{abstract}

Keywords: enzyme;leptin;lipid; liver; methadone; rat.

(c) 2021 by the authors. This article is an open-access article distributed under the terms and conditions of the Creative Commons Attribution (CC BY) license (https://creativecommons.org/licenses/by/4.0/).

\section{Introduction}

It is estimated that drugs are used once daily by nearly $5 \%$ of the world population that opioids and cannabis are the most harmful type and most widely used drugs respectively in the world [1]. Drug addiction is considered one of the most important public health problems of the 21 st century in the world also, in the Middle East countries, including Iran and Afghanistan $[2]$.

The number of people with substance use disorders (SUD) worldwide was reported 35 million individuals based on United Nations Office on Drugs and Crime (UNODC) statistics in 2017. In the United States in 2011, 20 million substance users imposed a total cost of \$193 
billion on society. Also, $\$ 193$ billion in total cost imposed by 20 million substance users on society in 2011 in the United States is estimated to be more than $\$ 330$ billion worldwide[3].

In this regard, substance use treatment is divided into medical detoxification, maintenance treatment, and management of intoxication [4]. Methadone Maintenance Therapy (MMT) has been accepted as a gold standard for reducing individual and public harms associated with opioid use in Iran and many other countries [5]. Maintenance therapy is often defined as long-term treatment of methadone (a long-acting $\mu$-opioid receptor agonist) to opiates drug-dependent, which may associate with adverse effects [5].

In recent years, the concept of gender-specific medicine (GSM) based on biological factors has been considered the foundation of precision medicine. It includes important differences in normal human biology and physiology between males and females and, herein, gender disparities in diagnostic and therapeutic responses [6]. Proportionately, it seems that sex differences should be considered in the addiction treatment field.

Lipid and methadone metabolism mostly occurs in the liver, which is later metabolized by cytochrome P450 enzymes; hence, methadone had adverse effects on liver function [7] in this context; the results studies about the effect of methadone on liver toxicity are contradictory. Hepatic enzymes of serum glutamic-pyruvic transaminase (SGPT), serum glutamicoxaloacetic transaminase (SGOT), and alkaline phosphatase (ALP), which there are in liver cells, are released in the bloodstream following hepatocyte injury [8].

Adipose tissue is a complex organ characterized not only as an inactive reservoir of energy but also as a fundamental endocrine gland of the human body with secreting many adipocyte-derived bioactive substances, namely adipokines [9]. Moreover, gender difference has been demonstrated in the concentration of some adipokines, including leptin, a protein hormone 16 [kDa], which is mainly secreted by white adipose tissue (WAT) [10]. Leptin levels reflect the amount of body fat and nutritional state through signaling to the hypothalamic satiety center to adjust food intake and energy expenditure accordingly [10].

Some studies have indicated changes in adipokines level with MMT and consequently changes in energy homeostasis. In the study by Montazerifar et al. on the 25 opioid addicts and 22 healthy controls, opioid addicts had significantly lower serum leptin levels than controls after 6 months MMT, the mean level of leptin increased dramatically [11].

Since methadone is the most widely used for MMT programs worldwide and maintenance therapy is often as long-term treatment may associate with adverse effects, this study aimed for the effect of methadone on lipid profile, serum leptin levels, and liver enzymes in male and female rats.

\section{Materials and Methods}

\subsection{Animals.}

In this experimental study performed at the Research Center of Experimental Medicine, Birjand University of Medical Sciences in Iran, 41 Wistar rats weighing 200-300 gr were studied. They acclimated at $25^{\circ} \mathrm{C}$ animal room with $12 \mathrm{~h}$ light-dark cycle (photoperiod; lights on, at 06:00 AM)for 1 week and was provided chow diet and water ad libitum during the experimental period. Rats were randomly assigned into four groups, including two groups methadone treatment and two control groups, both male and female that received methadone 5 $\mathrm{mg} / \mathrm{kg}$ on the day, 6 days in a week for 8 weeks by gavage method for induction of methadone dependence or $1 \mathrm{cc}$ normal saline respectively [12]. According to the weight of the animal's 
fresh stocks of methadone were prepared daily. During 8 weeks, treatment gavage of all animals was conducted at 12:00 PM on the day.

\subsection{Experimental protocol.}

All animals were weighed weekly. At the end of the study, using a glucometer (ACCUCHEK active model GC-Roche), fasting blood sugar (FBS) level was measured after $12 \mathrm{~h}$ of fasting from the tail of rats. Also, under anesthesia with ether, blood samples were taken from each rat by cardiac puncture for measurement of lipid profile (low-density lipoprotein (LDLC), high-density lipoprotein (HDL-C), triglyceride and total cholesterol, SGOT, SGPT, ALP, and leptin levels) after $12 \mathrm{~h}$ of fasting. Blood samples were centrifuged for 30 minutes for serum preparation then were stored at $-20{ }^{\circ} \mathrm{C}$ for subsequent analysis.

Methadone syrup was provided from Daru Pakhsh Co. (methadone $25 \mathrm{mg} / 5 \mathrm{ml}$ of 250 ml syrup; Darou Pakhsh Holding Co., Tehran, Iran). Using specifically available kits (Rat leptin ELISA Kit, Hangzhou EastbiopharmCo., Ltd) Serum leptin level was determined with a minimum sensitivity of $0.05 \mathrm{ng} / \mathrm{ml}$ with intra and inter-assay coefficients of variation less than $10 \%$ and $12 \%$, respectively. Lipid profile (HDL, LDL, triglyceride, and total cholesterol) and SGOT, SGPT, ALP levels were measured by Auto-analyzer Prestige 24i, Japan. After last administration, one male and female rat from methadone dependent groups randomly received $4 \mathrm{mg} / \mathrm{kg}$ naloxone $\mathrm{HCl}(0.4 \mathrm{mg} / \mathrm{ml}$; Toliddaru Pharma Co, Tehran, Iran) by intraperitoneal injection then were observed at 1 hour when were placed in a perspex box using a digital camera to record of withdrawal behaviors based on published criteria [13].

\subsection{Statistical analysis.}

All values are expressed as the mean $\pm \mathrm{S}$. D.data analysis was performed by SPSS software version 19. The Kolmogorov-Smirnov test was used for the assessment of the normal distribution of data. Statistical test of One-way ANOVA and Tukey's post hoc test was used for assessment of the significance of difference among groups. Also, the bodyweight of rats during 8 weeks was examined with repeated measures ANOVA, followed by Bonferroni post hoc test. Furthermore, correlation analysis was performed using Pearson's correlation test. In all of the tests, $p$-value was set at $5 \%$.

\section{Results and Discussion}

Based on Table1, there was no significant difference in fasting blood sugar (FBS), Total cholesterol, Triglyceride, and LDL levels among four groups ( $p>0.05)$, but HDL level was significantly lower in male methadone and male control groups than female methadone group respectively $(\mathrm{p}=0.003)$.

Table 1. Comparison of mean FBS, HDL, LDL, TG and total cholesterol in methadone treated and control group both female and male Wistar rats.

\begin{tabular}{|c|c|c|c|c|c|}
\hline \multirow{3}{*}{ Variables } & \multicolumn{4}{|c|}{ Groups } & \multirow[t]{3}{*}{ P-value } \\
\hline & \multicolumn{2}{|c|}{ Male Rat $(n=19)$} & \multicolumn{2}{|c|}{ Female Rat $(n=22)$} & \\
\hline & Methadone & Control & Methadone & Control & \\
\hline FBS (mg/dl) & $80.6 \pm 9.3$ & $81.8 \pm 6.4$ & $85.5 \pm 11.6$ & $80.5 \pm 3.1$ & 0.47 \\
\hline $\begin{array}{c}\text { Total Cholesterol } \\
(\mathrm{mg} / \mathrm{dl})\end{array}$ & $82.6 \pm 6.8$ & $78.3 \pm 7.1$ & $73.7 \pm 9.6$ & $73.9 \pm 10.6$ & 0.07 \\
\hline LDL (mg/dl) & $17.4 \pm 3.2$ & $17.4 \pm 2.2$ & $16.5 \pm 1.9$ & $16 \pm 2$ & 0.44 \\
\hline Triglyceride $(\mathrm{mg} / \mathrm{dl})$ & $80.7 \pm 11.7$ & $71.5 \pm 10.5$ & $78.6 \pm 14.6$ & $81.9 \pm 17.5$ & 0.42 \\
\hline
\end{tabular}




\begin{tabular}{c|c|c|c|c|c}
\multirow{2}{*}{ Variables } & \multicolumn{4}{|c|}{ Groups } & \multirow{2}{*}{ P-value } \\
\cline { 2 - 5 } & \multicolumn{2}{|c|}{ Male Rat (n=19) } & \multicolumn{2}{|c}{ Female Rat (n=22) } & \\
\cline { 2 - 5 } & Methadone & Control & Methadone & Control & \\
\hline HDL $(\mathrm{mg} / \mathrm{dl})$ & $34.8 \pm 3.6$ & $35.9 \pm 3.9$ & $41.6 \pm 4.4$ & $38.2 \pm 4.8$ & $0.003^{*}$
\end{tabular}

There was a significant difference in the mean ofSGOT, SGPT, and ALP levels among the four groups. SGOT and ALP levels were significantly higher in male methadone and male control groups than female methadone and female control groups, respectively $(p<0.001)$. SGPT level in the male methadone group was significantly higher than female methadone and female control groups, respectively $(\mathrm{p}=0.001)$. Also, the Leptin level in the male methadone group was significantly higher than the female control group ( $\mathrm{p}=0.034)$ (Table 2 ).

Table 2. Comparison of mean SGOT, SGPT, ALP, and Leptin in methadone treated and control group both female and male Wistar rats.

\begin{tabular}{|c|c|c|c|c|c|}
\hline \multirow{3}{*}{ Variables } & \multicolumn{4}{|c|}{ Groups } & \multirow[t]{3}{*}{ P-value } \\
\hline & \multicolumn{2}{|c|}{ Male Rat $(n=19)$} & \multicolumn{2}{|c|}{ Female Rat $(n=22)$} & \\
\hline & Methadone & Control & Methadone & Control & \\
\hline SGOT (mg/dl) & $307.4 \pm 31.9$ & $294.5 \pm 40.6$ & $212.6 \pm 46.9$ & $239.4 \pm 43.3$ & $<0.001^{*}$ \\
\hline SGPT (mg/dl) & $95.7 \pm 28.6$ & $89 \pm 23.1$ & $63.4 \pm 18.6$ & $62.2 \pm 16.6$ & $0.001 *$ \\
\hline $\operatorname{ALP}(\mathrm{mg} / \mathrm{dl})$ & $556.9 \pm 150.9$ & $590.4 \pm 165.8$ & $290.2 \pm 116.5$ & $208.4 \pm 83.1$ & $<0.001 *$ \\
\hline Leptin(ng/ml) & $0.49 \pm 0.08$ & $0.42 \pm 0.11$ & $0.42 \pm 0.06$ & $0.39 \pm 0.06$ & $0.034 *$ \\
\hline
\end{tabular}

Furthermore, during 8 weeks, there was a significant increase in the bodyweight of rats in four groups. The bodyweight of first-week male methadone and male control groups showed a significant difference in the next weeks' weight $(\mathrm{p}<0.001)$. However, in the female methadone group bodyweight of the first week had a significant difference with a bodyweight of the sixth, seventh and eighth weeks respectively $(\mathrm{P}=0.003)$ and in the female control group, bodyweight of the first week showed a significant difference with a bodyweight of the sixth week and third week with a sixth week $(\mathrm{P}=0.03)$ (Figure 1).

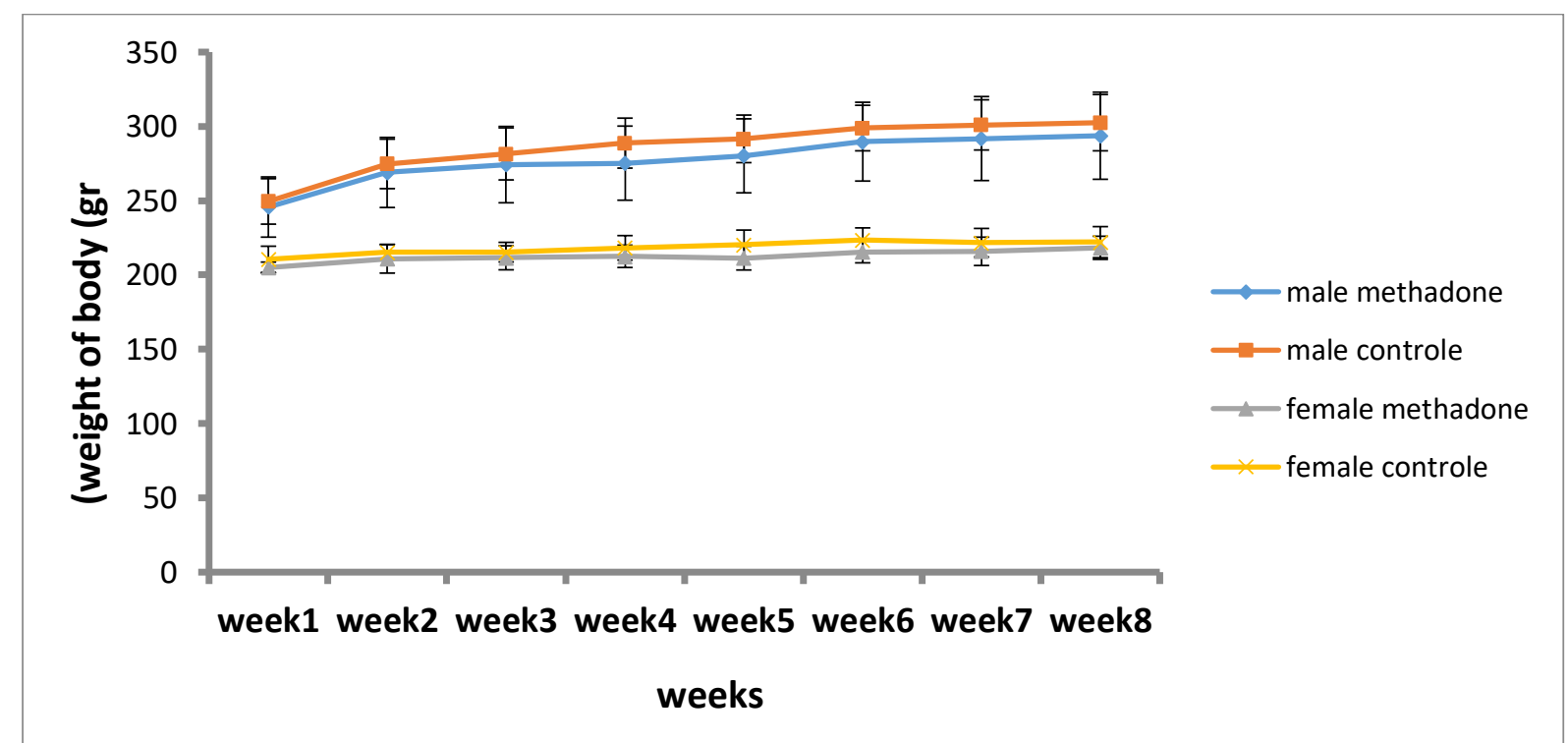

Figure 1. The effect of methadone administration on body weight of male and female Wistar rats during 8 weeks when compared with their same-sex control groups.

Also, we found a positive correlation between leptin and total cholesterol $(r=0.3$, $\mathrm{p}=0.04$ ) (Figure 2A) in addition, between leptin and SGOT, SGPT and ALP levels respectively 
$(\mathrm{r}=0.32, \mathrm{p}=0.036),($ Figure $2 \mathrm{~B})(\mathrm{r}=0.41 \mathrm{p}=0.007)($ Figure $2 \mathrm{C})$ and $(\mathrm{r}=0.33 \mathrm{p}=0.033)$ (Figure 2D).
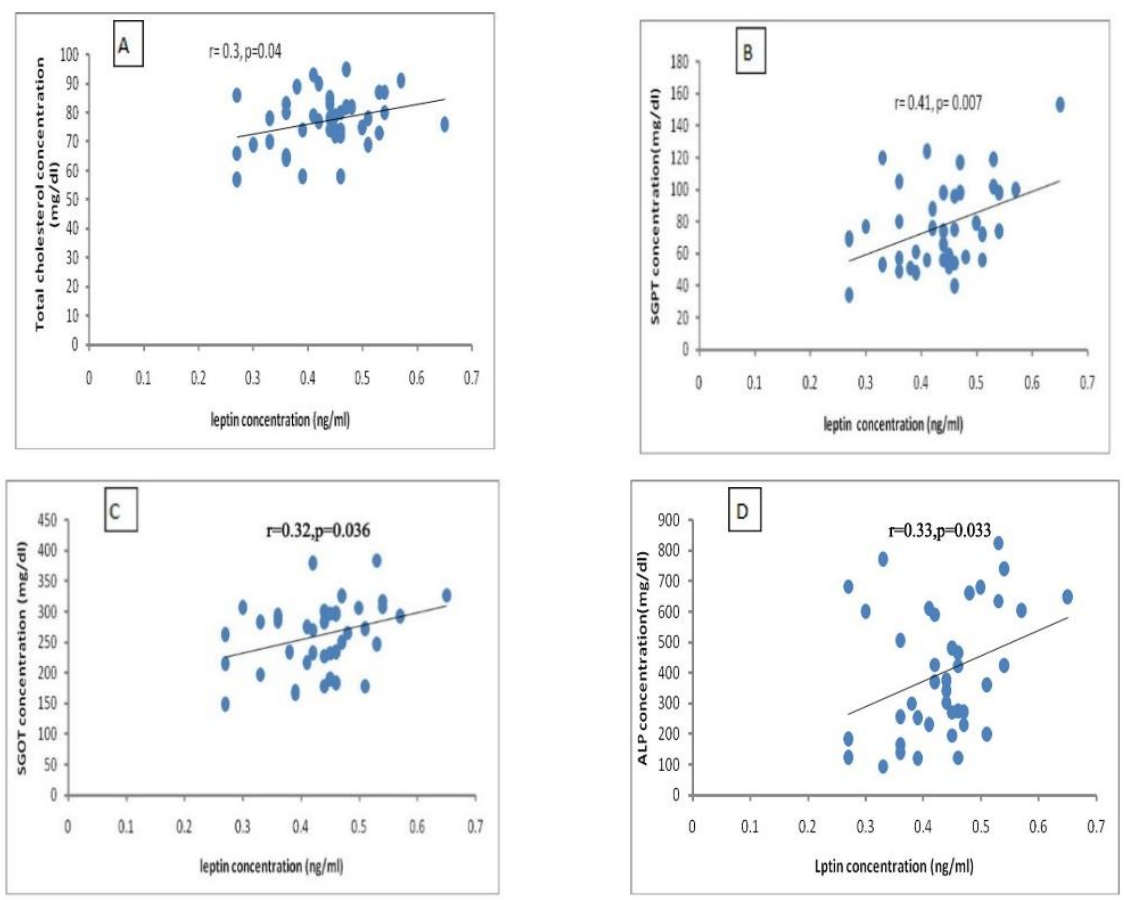

Figure 2. Correlation between serum total cholesterol, SGPT, SGOT, ALP concentration, and serum leptin concentration, respectively $(\mathrm{A}, \mathrm{B}, \mathrm{C}$, and $\mathrm{D})$ in male and female Wistar rats.

Histological examination of liver sections of methadone-treated animals (both sexes) showed no evident alteration in hepatocytes, sinusoidal spaces, and portal triads (Figure 3).

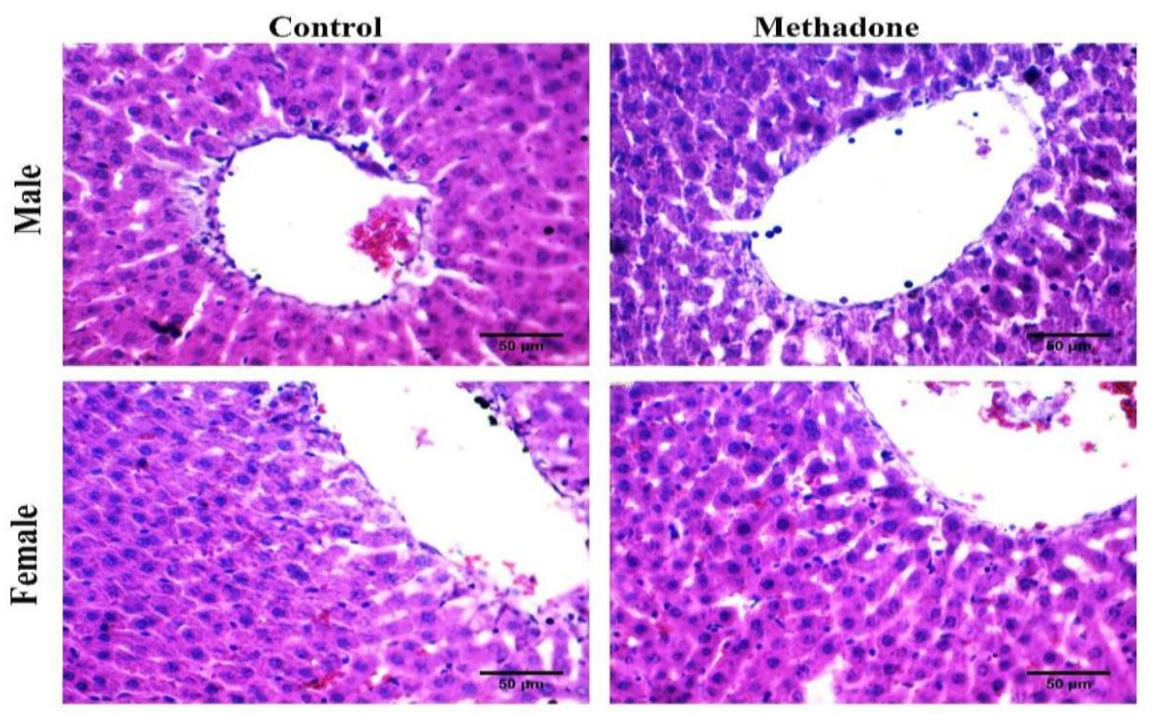

Figure 3. Histopathological assessment of livers of control and methadone treated rats. The micrographs show a normal liver structure in which hepatocytes are arranged radially around the central vein with no evidence of hemorrhage, congestion, necrosis, or pathological damage. Haematoxylin and eosin staining, 400X magnification (scale-bar $=50 \mu \mathrm{m})$.

In our study, there was no significant difference in FBS levels among the four groups. Our study supports the results by Sadava et al. (1997) on female albino rats with methadone addition in their drinking water [14], and it is inconsistent with a recent study by Tahergorabi et al. on 40 Wistar rats that methadone was injected intraperitoneally for 10 consecutive days at $5 \mathrm{mg} / \mathrm{kg}$ dose [15]. The differences between this study and mentioned studies can be due to 
factors including route of treatment and duration of drug dependency, which can change serum glucose.

Our results showed no significant difference in total cholesterol, triglyceride aand LDL levels among the four groups; moreover, HDL level was significantly lower in male methadone and male control groups than female methadone groups. Our result is in accordance with a recent study conducted by Elman et al. on subjects treated with buprenorphine $(\mathrm{n}=26)$ or methadone $(\mathrm{n}=32)$ with opioid use disorder [16] and is in contrast with the study by Montazerifar et al. (2014) on the 25 opioid addicts and 22 healthy controls [11].

It is noteworthy, important differences between human and rat lipoproteins, including the presence of the E apoprotein as a major protein component of rat HDL (an anti-atherogenic lipoprotein) while human HDL has only small amounts of the E apoprotein. Also, in rats, HDL is the predominant class of lipoproteins, and it is responsible for carrying the majority of the plasma cholesterol despite humans that most of the plasma cholesterol is transported by LDL [17]. On the other hand, previous studies have shown that estrogen has no effect on immature plasma cholesterol levels compared with adult rats. Estrogen receptors alpha (ER $\alpha)$ and beta $(\mathrm{ER} \beta)$ are involved in many physiological functions of estrogen [18]. It upregulates mRNA expression of scavenger receptor class B member (SR-BI), the HDL receptor, and promotes HDL-cholesterol uptake. Accordingly, HDL capacity for cholesterol efflux decreased in hepatocyte estrogen receptor knockout (LKO-ERa) female mice [19].

Our study indicated that SGOT and ALP levels were significantly higher in male methadone and male control groups than in female methadone and female control groups. SGPT level in the male methadone group was significantly higher than female methadone, and female control groups had a positive correlation with leptin levels. Our study is in agreement with the study Eslami-Shahrbabaki et al. (2012) on 94 patients undergoing MMTthat liver enzyme levels in all patients were tested until 24 months [20] and is in contrast with a threeyear-long study by Kreek et al. (1972) on patients with high doseMMT that none of the 129 patients who completed the study showed signs of hepatotoxicity by methadone [21].

Most pain relief medications, including methadone, are metabolized exclusively in the liver through CYP3A4 CYP2D6, CYP2B6, CYP2C19, and CYP1A2 liver enzymes(cytochrome p450s; xenobiotics oxidizing enzyme), and this typically results in multiple metabolites which can impact the normal function of animal and human liver enzymes [22].It is noteworthy that sex hormones regulate CYP enzymes of CYP2C19 and CYP2B6; therefore, methadone metabolism linked with MMT program is gender-dependent [22].

Furthermore, three enzymes of SGOT, SGPT, and ALP have a much higher value in rats than in humans, and on the other hand, there is the sex difference in SGOT, SGPT, and ALP levels in male and female rats such that male rats have higher SGOT, SGPT, and ALP levels than female rats in the course of life [23]. Accordingly, in our study, both male methadone and control groups had higher SGOT, SGPT, and ALP levels than female methadone and control groups. Our findings indicated a positive correlation between SGOT, SGPT, ALP levels, and leptin.

Previous studies have demonstrated significant correlations between liver markers SGOT, SGPT, ALP, and metabolic syndrome in turn related to leptin levels [24]. Leptin as a $16 \mathrm{kDa}$ adipokine acts as a hormone and cytokine that can exert a proinflammatory role in rats and mice [25]; therefore, it is considered an essential mediator of liver fibrosis [24]. 
Our study shows that the significant positive correlation between serum leptin levels and total cholesterol and leptin level in the male methadone group was significantly higher than the female control group.

Serum leptin concentrations are associated with body fat content, and gender plays an important role in determining leptin concentration. In our study male methadone group had a higher leptin level than a female control group that it is in agreement with Muletet al. (2003) [26] and is inconsistent with one study by Machinal et al. (1999) that found no differences in circulating leptin levels between male and female rats [27]. A possible explanation is the existence of sexual dimorphism in rat leptin levels contrary to what happens in humans, which may be related to differences in the distribution and extent of fat stores in rats and humans. Another explanation is leptin levels are related to sex hormones which can be another explanation [10].

Our findings demonstrated that during 8 weeks, there was a significant increase in the body weight of rats in four groups. Our study is in line with the study by Mysels et al. (2011) that patients during the first 6 months of methadone treatment showed 10-pound weight gain [28] and is in contrast with the study by Kolarzyk et al. (2005) that showed in female patients a modest weight loss moreover, a modest weight gain in males [29]. A possible explanation can be attributed to preclinical and clinical studies that have shown administration of muagonist or activation of the mu-opiate receptor is associated with increased sugar intake, highsugar foods preference, possibly the accumulation of body fat and weight gain, and eventually potential insulin resistance [30].

Finally, histological examination of liver sections of methadone-treated animals (both sexes) showed no evident alteration in hepatocytes, sinusoidal spaces, and portal triads that may take longer for treatment to cause histological changes.

\section{Conclusions}

In conclusion, our findings indicated some metabolic effects associated with methadone treatment in a gender-dependent manner. Therefore, a number of factors are involved for effective and successful methadone maintenance treatment programs, including gender differences that should consider by clinicians.

\section{Funding}

This research received no external funding.

\section{Acknowledgments}

Current work was supported by the Research Council of Birjand University of Medical Sciences (the research Project No. [456055].

\section{Conflicts of Interest}

We authors have no conflicts of interest to declare that they are relevant to the content of this article. 


\section{References}

1. United Nations Office on Drugs and Crime (UNODC). World Drug Report 2019 (United Nations publication, Sales No. E. 19. XI. 8), https://www.unodc.org/res/wdr2021/field/WDR21_Booklet_1.pdf.

2. Amirabadizadeh, A.; Nezami, H.; Vaughn, MG.; Nakhaee, S.; Mehrpour, O. Identifying risk factors for drug use in an Iranian treatment sample: A prediction approach using decision trees. Substance use \& misuse 2018, 53, 1030-1040, https://doi.org/10.1080/10826084.2017.1392981.

3. Moghaddam, S.A.; Roshanpajouh, M.; Mazyaki, A.; Amiri, M.; Razaghi, E. Subsidization of substance use treatment: Comparison of methadone maintenance treatment and abstinence-based residential treatment in Iran. Iran. J. Psychiatry. Behav. Sci. 2020, 14, https://doi.org/10.5812/ijpbs.98718.

4. Patel, K.; Bunachita, S.; Agarwal, AA.; Lyon, A.; Patel, UK. Opioid Use Disorder: Treatments and Barriers. Cureus. 2021, 13, e13173, https://doi.org/10.7759/cureus.13173.

5. Durand, L.; Boland, F.; O'Driscoll, D.; Bennett, K.; Barry, J.; Keenan, E.; Fahey, T.; Cousins, G. Factors associated with early and later dropout from methadone maintenance treatment in specialist addiction clinics: a six-year cohort study using proportional hazards frailty models for recurrent treatment episodes. Drug Alcohol Depend. 2021, 219, 108466, https://doi.org/10.1016/j.drugalcdep.2020.108466.

6. Saxon, AJ. Potential for Precision Medicine in Methadone Treatment of Opioid Use Disorder. J. Addict. Med. 2020, 14,362-363, https://doi.org/10.1097/ADM.0000000000000619.

7. Ramli, FF. Pharmacogenomics biomarkers for personalized methadone maintenance treatment: The mechanism and its potential use. Bosn J Basic Med Sci. 2021, 21, 145, https://doi.org/10.17305/bjbms.2020.4897.

8. Macpherson, I.; Nobes, JH.; Dow, E.; Furrie, E.; Miller, MH.; Robinson, EM.; Dillon, JF. Intelligent liver function testing: Working smarter to improve patient outcomes in liver disease. J Appl Lab Med. 2020, 5, 1090-1100, https://doi.org/10.1093/jalm/jfaa109.

9. Chait, A.; den Hartigh, L.J. Adipose tissue distribution, inflammation and its metabolic consequences, including diabetes and cardiovascular disease. Front cardiovasc med. 2020, 7, 22, https://doi:org/10.3389/fcvm.2020.00022.

10. Gavin, K.M.; Bessesen, D.H. Sex differences in adipose tissue function. Endocrinol. Metab. Clin. 2020, 49 , 215-228, https://doi.org/10.1016/j.ecl.2020.02.008.

11. Montazerifar, F.; Karajibani, M.; Lashkaripour, K.; Yousefi, M. Effects of Methadone Maintenance Therapy (MMT) on Serum Leptin, Lipid Profile, and Anthropometric Parameters in Opioid Addicts. Heroin Addict Relat Clin Probl. 2014, 16, 9-16, https://idhdp.com/media/1298/heroin-addiction-and-related-clinicalproblems-.pdf\#page $=11$.

12. Amraei, M.; Mohamadpour, M.; Ahmadi, M.R.H.; Azizi, M.; Daemi, A.; Omidi, M.;Shirzadpour,E. Histopathological study of liver tissue due to methadone consumption and its effect on liver enzymes and inflammatory indices in rat. Drug Des. Dev. Ther. 2018, 12, 3785, https://doi.org/10.2147/DDDT.S182032.

13. Ebrahimi, B.; Esmaeili-Mahani, S. The Effects of Hydroalcoholic Extract of Satureja khuzestanica on Naloxone-Induced Morphine Withdrawal Symptoms in Wistar Rats. Int. j. basic appl. med. sci. 2020, 5, 1621, https://doi.org/10.34172/ijbsm.2020.05.

14. Sadava, D.; Alonso, D.; Hong, H.; Pettit-Barrett, D. Effect of methadone addiction on glucose metabolism in rats. Vasc. Pharmacol: The Vasc Sys 1997, 28, 27-29, https://doi.org/10.1016/S0306-3623(96)00165-6.

15. Tahergorabi, Z.; Rahmani, H.; Williams, J.; Moodi, M. The effect of methadone on blood glucose, lipids and glucose-modulating hormones in methadone-dependent Wistar rats. Toxicol Res. 2020, 36, 221-226, https://doi.org/10.1007/s43188-019-00019-z.

16. Elman, I.; Howard, M.; Borodovsky, J.T.; Mysels, D.; Rott, D.; Borsook, D.; Albanese, M. Metabolic and Addiction indices in patients on opioid Agonist Medication-Assisted treatment: A comparison of Buprenorphine and Methadone. Sci. Rep. 2020, 10,1-12, https://doi.org/10.1038/s41598-020-62556-0.

17. Konishi, T.; Takahashi, Y. Lipoproteins comprise at least 10 different classes in rats, each of which contains a unique set of proteins as the primary component. PloS one 2018, 13, e0192955, https://doi.org/10.1371/journal.pone.0192955.

18. Lundeen, S.G.; Carver, J.M.; McKean, M.L.; Winneker, R.C.J.E. Characterization of the ovariectomized rat model for the evaluation of estrogen effects on plasma cholesterol levels.Endocrinol. 1997, 138, 1552-1558, https://doi.org/10.1210/ENDO.138.4.5083.

19. Zhu, L.; Shi, J.; Luu, T.N.; Neuman, J.C.; Trefts, E.; Yu, S.; Palmisano, B.T.; Wasserman, D.H.; Linton, M.F.; Stafford, J.M. Hepatocyte estrogen receptor alpha mediates estrogen action to promote reverse cholesterol transport during Western-type diet feeding. Mol. Metab 2018, 8, 106116,https://doi.org/10.1016/j.molmet.2017.12.012.

20. Eslami-Shahrbabaki, M.; Haghdoost, AA.; Mashaiekhi, A.; Khalili, N.; Amini-Ranjbar, Z.; Ghayomi, A. Effects of methadone on liver enzymes in patients undergoing methadone maintenance treatment. Addiction \& health. 2012, 4, 111 .

21. Kreek, M.J.; Dodes, L.; Kane, S.; Knobler, J.; Martin, R. Long-term methadone maintenance therapy: effects on liver function. Ann. Intern. Med. 1972,77,598-602, https://doi.org/10.7326/0003-4819-77-4-598. 
22. Chang, H.W.; Ho, W.C.; Huang, C.L.; Wang, R.Y. Precision therapeutic opioid dosing implications from genetic biomarkers and craving score. Medicine 2020, 99, e20429, https://doi.org/10.1097/MD.0000000000020429.

23. Eurich, R.; Lindner, J.; Schröder, S. Investigations of metabolic parameters in male and female rats during the course of life. Mech Ageing Dev 1980,14, 317-323, https://doi.org/10.1016/0047-6374(80)90005-6.

24. Martínez-Uña, M.; López-Mancheño, Y.; Diéguez, C.; Fernández-Rojo, M.A.; Novelle, M.G. Unraveling the Role of Leptin in Liver Function and Its Relationship with Liver Diseases. Int. J. Mol. Sci. 2020, 21, 9368, https://doi.org/10.3390/ijms21249368.

25. Jiménez-Cortegana, C.; García-Galey, A.; Tami, M.; Del Pino, P.; Carmona, I.; López, S.; Alba, G.; SánchezMargalet, V. Role of Leptin in Non-Alcoholic Fatty Liver Disease. Biomedicines 2021, 9, 762, https://doi.org/10.3390/biomedicines9070762.

26. Mulet, T.; Picó, C.; Oliver, P.; Palou, A. Blood leptin homeostasis: sex-associated differences in circulating leptin levels in rats are independent of tissue leptin expression. Int. J. Biochem. Cell Biol.2003, 35, 104-110, https://doi.org/10.1016/s1357-2725(02)00092-4.

27. Machinal, F.; Dieudonne, M.N.; Leneveu, M.C.; Pecquery, R.; Giudicelli, Y. In vivo and in vitro ob gene expression and leptin secretion in rat adipocytes: evidence for a regional specific regulation by sex steroid hormones. Endocrinology 1999, 140, 1567-1574, https://doi.org/10.1210/endo.140.4.6617.

28. Mysels, D.J.; Vosburg, S.; Benga, I.; Levin, FR.; Sullivan, M.A. Course of weight change during naltrexone vs. methadone maintenance for opioid-dependent patients. J Opioid Manag2011,7,47.

29. Kolarzyk, E.; Pach, D.; Wojtowicz, B.; Szpanowska-Wohn, A.; Szurkowska, M. Nutritional status of the opiate dependent persons after 4 years of methadone maintenance treatment. Przeglad lekarski, 2005, 62,3737.

30. Garfield, JBB.; Lubman, DI. Associations between opioid dependence and sweet taste preference. Psychopharmacology (Berl) 2021, 238, 1473-1484 https://doi.org/10.1007/s00213-021-05774-2. 